\title{
EPIDEMIOLOgicAl CHANGES IN OESOPHAgEAL CANCER AT NATIONAL Hospital, BloEMFONTEIN: 1995, 2000 AND 2005
}

\author{
Authors: \\ Tian van der Merwe ${ }^{1}$ \\ Ruan van der Walt ${ }^{1}$ \\ Jován Esterhuizen ${ }^{1}$ \\ Stephani Botha ${ }^{1}$ \\ Louis Goedhals ${ }^{2}$ \\ Gina Joubert ${ }^{3}$
}

\section{Affiliations:}

${ }^{1}$ Faculty of Health

Sciences, University of the

Free State, South Africa

${ }^{2}$ Department of Oncotherapy, University

of the Free State, South

Africa

${ }^{3}$ Department of Biostatistics, University of the Free State, South Africa

Correspondence to:

Gina Joubert

email:

gnbsgj.md@ufs.ac.za

\section{Postal address:}

Department of Biostatistics (G31), University of the Free State, PO Box 339,

Bloemfontein 9300,

South Africa

\section{Keywords:}

cancer; carcinoma; epidemiology; incidence; oesophagus

\section{Dates:}

Received: 22 June 2008

Accepted: 14 Nov. 2009

Published: 11 June 2010

How to cite this article: Van der Merwe T, Van der Walt R, Esterhuizen J, Botha S, Goedhals L, Joubert G. Epidemiological changes in oesophageal cancer at National

Hospital, Bloemfontein: 1995, 2000 and 2005. Afr J Prm Health Care Fam Med. 2010;2(1), Art. \#100, 5 pages. DOI: 10.4102 / phcfm.v2i1.100

\section{This article is available} at: http://www.phcfm.org

(c) 2010. The Authors. Licensee: OpenJournals Publishing. This work is licensed under the

Creative Commons

Attribution License.

\section{ABSTRACT}

Background: Oesophageal cancer is a common malignancy with a high mortality rate. The two main histological types are squamous cell and adenocarcinoma. An increase in oesophageal adenocarcinoma has been noted, especially in developed countries.

Objectives: The aim of this retrospective study was to investigate the profile of oesophageal cancer by reviewing medical records of patients diagnosed with oesophageal cancer in 1995, 2000 and 2005.

Method: The study sample consisted of 474 files of patients diagnosed, for the first time, with oesophageal cancer in 1995, 2000 and 2005, at the National Hospital in Bloemfontein and the outreach clinics in surrounding areas. Information reviewed from patient files included: age, race and gender of the patient, as well as topography, size, histological grade and type of the tumour.

Results: The number of newly diagnosed cases of oesophageal carcinoma decreased over the 10year period. The mean age of patients was $>57$ years. The majority of cases were Black patients: $90.5 \%$ in $1995,93.2 \%$ in 2000 and $87.7 \%$ in 2005 . More male patients were seen $(71.5 \%$ in $1995,70.1 \%$ in 2000 and $64.2 \%$ in 2005), although the number of female patients diagnosed with this malignancy increased by $7.3 \%$ from 1995 to 2005 . The mid- and lower third of the oesophagus were affected most commonly, most lesions were $6 \mathrm{~cm}-10 \mathrm{~cm}$ in length and classified as Grade II, moderately differentiated tumours. Squamous cell carcinoma was diagnosed in $76.9 \%$ of patients in $1995,90.5 \%$ in 2000 and $94.3 \%$ in 2005 .

Conclusion: The number of newly diagnosed cases of oesophageal carcinoma decreased over the 10 -year period, but demographic and disease characteristics remained constant.

\section{INTRODUCTION}

Two histological types of oesophageal cancer that occur most frequently are squamous cell carcinoma and adenocarcinoma. Squamous cell carcinoma originates from the epithelium lining the oesophagus, while the malignant epithelial cells in adenocarcinoma are arranged in a glandular formation. In the past, squamous cell carcinoma occurred more frequently, but, over the past couple of decades, an increase in adenocarcinoma of the oesophagus has been noted. ${ }^{1}$ However, no reports of previous studies explaining this observation could be found in the literature.

Huang $^{2}$ classified the natural history of oesophageal cancer into four different phases. The initial phase of oesophageal carcinoma stretches over an extended period, probably 20 years or more. The first changes that occur are small to moderate hyperplasia of the basal epithelial cells of the oesophageal mucosa. This is followed by the developmental phase in which cancerous cells develop. The developmental phase is clinically latent and may be present for a long period of time. These cells penetrate the basal layer of the epithelium and develop into infiltrating cancer that occurs as a granular plaque. Thereafter, the disease progresses to the overt phase, which is the main clinical phase that includes stages two and three of oesophagus carcinoma. In some cases, the primary cancer enlarges from the originally small, localised, early lesion. This lesion penetrates the deep layers of the oesophageal wall during the process of development. The primary cancer can also develop from a superficial lesion and increase rapidly in size, with penetration of the deeper layers of the oesophagus. The final phase of oesophageal carcinoma is usually short, with extensive extra-oesophageal invasion to the vital organs, for example, metastasis to the lungs. ${ }^{2}$

Three screening modalities are available for early identification of oesophageal cancer: routine double contrast radiology, fibre-optic endoscopy, and oesophageal cytology. Oesophageal endoscopy employs the brush or balloon method, which has been found to show $95 \%$ accuracy in the identification of oesophageal cancer. The combination of balloon cytology and fibre-optic endoscopy provides a solid foundation for the early diagnosis of dysplasia and premalignant lesions. ${ }^{2}$

The diagnosis of oesophageal cancer is often made late, when screening is no longer beneficial. In countries with a high incidence of oesophagus carcinoma, such as China, population screening programmes may be employed. In Western countries, however, where the incidence is usually lower, these screening programmes are not always applied. ${ }^{2}$

Different factors are associated with oesophageal cancer and various studies across the world have been conducted to investigate these associations. A patient's ethnicity plays an important role, which is illustrated by the drastic difference between the incidence of oesophageal cancer in Black and White ethnic groups. ${ }^{3}$ Oesophageal cancer in Black South Africans was very rare until the last couple of decades. ${ }^{4}$ In South African Black men, for example, the incidence of oesophageal cancer is 40.9 per 100000 males, compared to 4.4 per 100000 males in Mozambique and 1.5 per 100000 males in Nigeria. ${ }^{5}$ 
According to a case-control study performed in Soweto, South Africa, involving 200 oesophageal cancer patients and 391 hospital controls, pipe tobacco and the consumption of traditional beer were identified as risk factors for rural Black populations. ${ }^{4}$ Although other research supported tobacco smoking as a risk factor, ${ }^{6}$ a study conducted in Sweden found that alcohol consumption does not have an effect on the development of oesophageal carcinoma. ${ }^{7}$

Several studies were performed to determine whether food types have an effect on the incidence of oesophageal carcinoma. It was found that people consuming insufficient amounts of fruit or cereals, ${ }^{7}$ vegetables ${ }^{2}$ or excessive amounts of meat, ${ }^{8}$ were at greater risk of oesophageal cancer. Chronic malnutrition was also found to increase the risk of oesophageal carcinoma. ${ }^{3}$

A case-control study conducted in Sweden between 1995 and 1997, found that first degree family members did not have an increased risk of cancer in both adenocarcinoma and squamous cell oesophageal carcinoma cases. ${ }^{9}$ On the contrary, a British study on the incidence of oesophageal carcinoma found that heredity did, in fact, play a role, albeit to a minor extent.

The aim of this retrospective study was to investigate the profile of oesophageal cancer by reviewing medical records of patients diagnosed with oesophageal cancer in 1995, 2000 and 2005.

\section{METHOD}

A retrospective analytical study was performed to review medical records for the years 1995, 2000 and 2005. Four hundred and seventy-four files of patients diagnosed with oesophageal cancer for the first time in these years, at the Department of Oncotherapy at the National Hospital in Bloemfontein and outreach clinics in Bethlehem, Kimberley, Kroonstad and Welkom, were included in the study. Files were made available by the Biostatistics Division of the National Hospital. Information regarding the demography of patients, as well as the topography and morphology of the cancer, were obtained from the patients' files and recorded in a data sheet.

Analysis of data was performed by the Department of Biostatistics, University of the Free State, using SAS software. ${ }^{10}$ Results of categorical variables were summarised as frequencies and percentages, and numerical variables as means, standard deviations or percentiles. The three different years (1995, 2000 and 2005) were compared by means of analysis of variance, Fischer's exact or chi-square tests, as appropriate.

The research protocol was approved by the Ethics Committee of the Faculty of Health Sciences, University of the Free State (ETOVS Stud. Nr. 26/07). Permission was also obtained from the Head of Clinical Services of the Universitas Academic Complex, which includes the National Hospital. Data obtained remained confidential, patients' anonimity being preserved through indicating only their oncotherapy reference number on the data form.

A pilot study was performed on 20 patient files from 1998 in order to assess certain aspects of the study, such as the availability of resources (funds and personnel), the amount of time required to complete the data sheet, and the executability of each step of the study. The pilot study also provided an indication of possible results that were to be anticipated.

\section{RESULTS}

The number of patients diagnosed with oesophageal carcinoma for the first time decreased across the study period. In 1995, 221 cases were diagnosed, in 2000, 147 cases and in 2005, 106 cases. The mean age of patients was 57.8 years and 57.5 years in 1995 and 2000, respectively, while a slight increase in the mean age (59.6 years) was observed in $2005(p=0.2758)$.

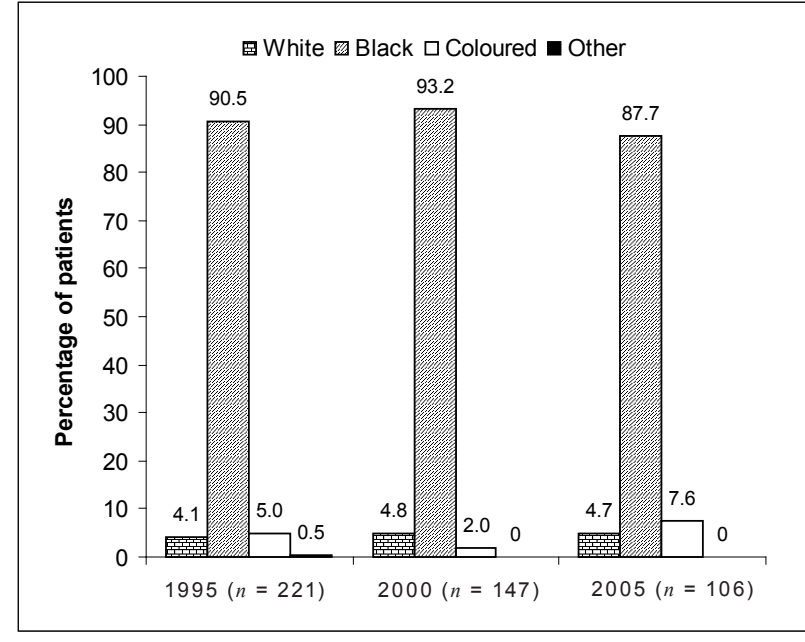

FIGURE 1

Racial distribution of patients diagnosed with oesophageal cancer in 1995, 2000 and 2005

aUpper 1/3 घ Middle 1/3 囵Lower 1/3 a Point of origin not determined

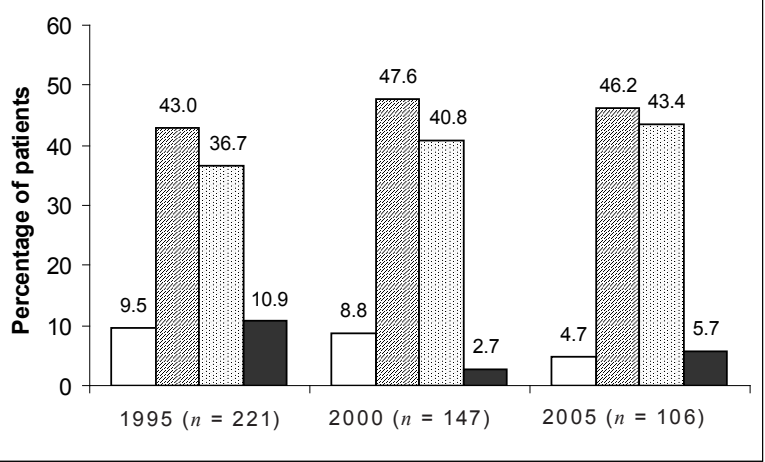

FIGURE 2

Topographic distribution of oesophageal cancer in 1995, 2000 and 2005

Male patients were in the majority over the entire period of time, with $71.5 \%, 70.1 \%$ and $64.2 \%$ of patients being male in 1995 , 2000 and 2005, respectively. A slight increase in female patients was noted over the 10 -year period, with $28.5 \%$ of patients being female in $1995,29.9 \%$ in 2000 and $35.8 \%$ in 2005.

The vast majority of patients diagnosed with oesophageal cancer were Black $(90.5 \%$ in $1995,93.2 \%$ in 2000 and $87.7 \%$ in 2005). Results of patient distribution according to race are shown in Figure 1.

The results showed that the parts of the oesophagus most commonly affected by cancer were the middle and lower third, while involvement of the upper third of the oesophagus remained below $10 \%$ for the three years investigated. The topographic distribution of oesophageal cancer in 1995, 2000 and 2005 is shown in Figure 2.

The length of the tumour was either unknown or not indicated in the patients files in a total of 139 cases $-31.7 \%, 32 \%$ and $20.8 \%$ of patients in 1995, 2000 and 2005 respectively. The results of the tumour length in cases where this information was available are shown in Figure 3.

Figure 4 shows the distribution of the different histological grades of tumours in oesophageal carcinoma between 1995, 2000 and 2005. The histological grade of the tumour was unknown in 


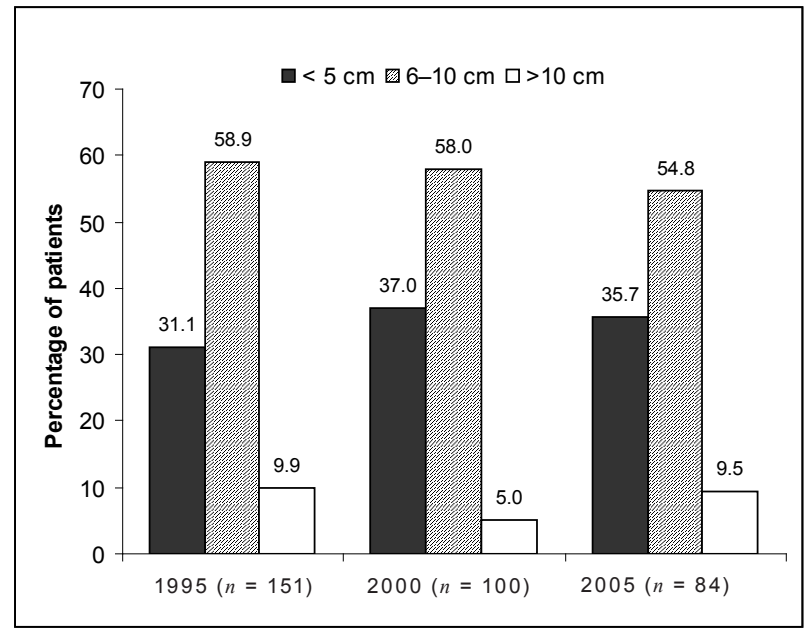

FIGURE 3

Length of the tumour in oesophageal carcinoma in 1995, 2000 and 2005

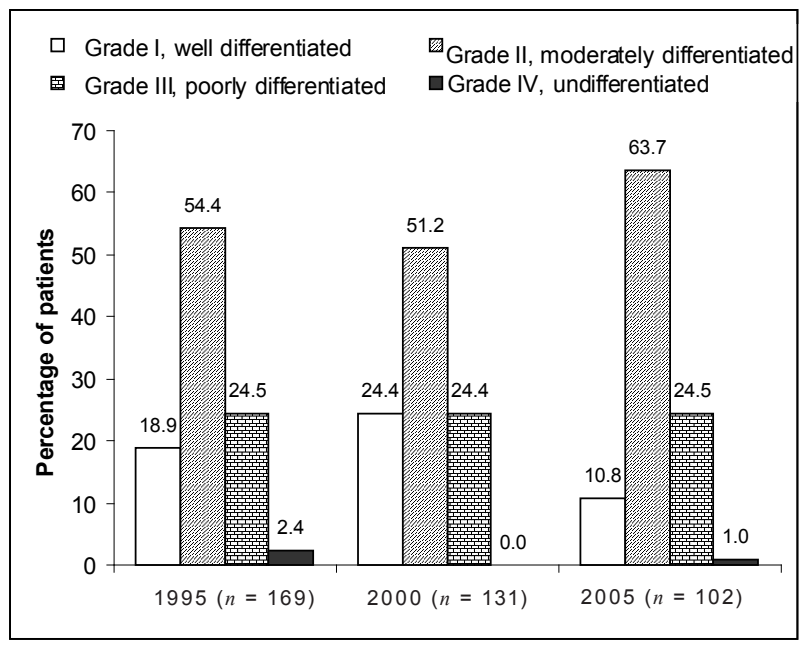

FIGURE 4

Histological grade of tumours in oesophageal cancer in 1995, 2000 and 2005

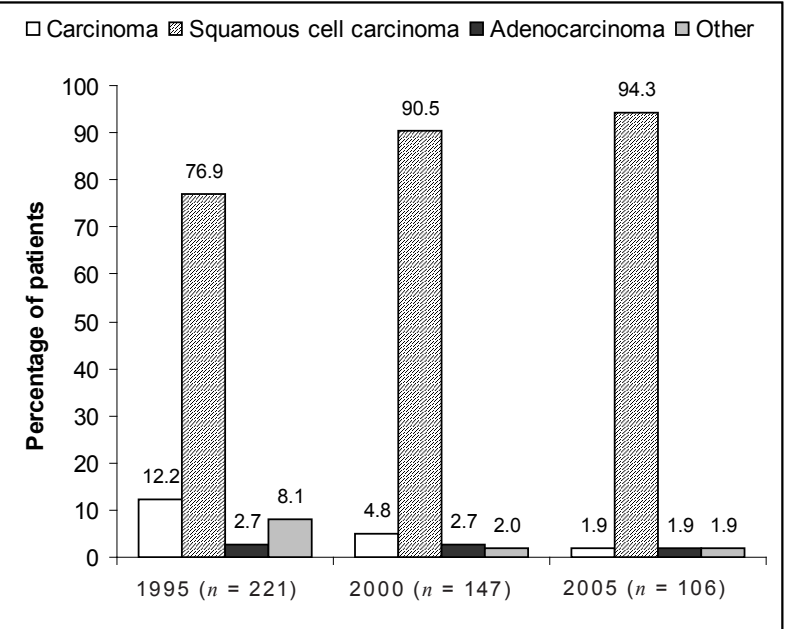

FIGURE 5

Distribution of different morphological types of oesophageal carcinoma in 1995, 2000 and 2005

72 patients $-23.5 \%, 10.9 \%$ and $3.8 \%$ of patients in 1995,2000 and 2005 , respectively. More than $50 \%$ of patients in each of these years were diagnosed with Grade II, moderately differentiated tumours.
With regard to the morphological type of oesophageal carcinoma, the majority of patients were diagnosed with squamous cell carcinoma $-76.9 \%$ in $1995,90.5 \%$ in 2000 and $94.3 \%$ in 2005 (Figure 5). In a small number of patients, the specific morphological type was either not indicated (i.e. indicated only as 'carcinoma' in the patient file) or indicated as 'other'. This occurred more often in the patient files from 1995.

Information regarding the development of fistulae in patients with oesophageal carcinoma was not available in 268 (56.5\%) cases $-47.5 \%$ in $1995,62.6 \%$ in 2000 and $67 \%$ in 2005 . The majority of patients for whom information was available, however, did not develop fistulae, with this complication being observed in $20.7 \%$ of patients in $1995,43.6 \%$ in 2000 and $31.4 \%$ in 2005. In $319(67.3 \%)$ cases (52\% in $1995,83 \%$ in 2000 and $77.4 \%$ in 2005), no information regarding the development of sinuses was indicated in the patients' files. Of those for whom information was available, $28.3 \%$ developed sinuses in $1995,60 \%$ in 2000 and $42.7 \%$ in 2005 .

Metastasis occurred in less than $40 \%$ of the patients for whom information was available ( $n=180 ; 38.0 \%)$, with $37.7 \%$ in 1995 , $31.3 \%$ in 2000 and $29.8 \%$ in 2005 . In cases where metastasis occurred, the lungs were involved in $43 \%$ and lymph nodes in $31 \%$ of patient cases.

Of the $389(82.1 \%)$ patients for whom information was available, more than $90 \%$ reported weight loss $-96.1 \%$ in $1995,93.3 \%$ in 2000 and $96.7 \%$ in 2005 . In each year, more than $85 \%$ of patients were diagnosed with Grade I dysphagia, with $89.6 \%$ in 1995, $86.4 \%$ in 2000 and $94.3 \%$ in $2005 ; 9.6 \%, 10.2 \%$ and $1.9 \%$ of patients did not experience any dysphagia in these three years respectively. These differences between 1995 and the other two years were statistically significant $(p=0.0022)$.

Based on the Eastern Cooperative Oncology Group (ECOG) performance status of patients with malignant diseases, less than $20 \%$ of the 330 patients for whom this information was available were evaluated as Grade 0, that is, they were fully active and able to carry out all pre-disease activities without restriction. ${ }^{11}$ Results for ECOG performance status grading of the patients investigated in 1995, 2000 and 2005 are summarised in Table 1.

Information regarding the presence of co-morbid disease was available for $328(69.2 \%)$ patients. The most commonly reported co-morbidity was respiratory disease, which occurred in $28.2 \%$ of the patients for whom information was available in 1995, $45.6 \%$ in 2000 and $28.7 \%$ in 2005 (Figure 6).

Information regarding the latest cancer status of these patients was available in $41.6 \%(n=197)$ of the files. Of these, progression of the disease was noted in $51.9 \%$ of patients in $1995,45.5 \%$ in 2000 and $69.2 \%$ in 2005 .

The development of complications following therapy was unknown for $75.1 \%$ of the total group of patients. By the time of completion of the study, 65\% of both the 1995 and 2005 patients had not returned for any follow-up visit, as opposed to $36 \%$ of the 2000 group of patients. Of those for whom followup information was available, $62 \%$ of the 2000 group of patients were deceased, compared to 30\% of both the 1995 and 2005 patients.

\section{DISCUSSION}

The decrease of $52 \%$ in the number of newly diagnosed cases of oesophageal carcinoma, from 221 cases in 1995 to 106 cases in 2005 , could be attributed to several possible reasons. A possible explanation could be that, with the emergence of the HIV/ AIDS epidemic in southern Africa, many potential patients died of HIV/AIDS-related diseases before they reached the age at which oesophageal cancer is most commonly diagnosed, which is approximately 60 years of age. ${ }^{12,13}$ Most HIV/AIDS-related 
TABLE 1

Grading of Eastern Cooperative Oncology Group (ECOG) performance status of patients diagnosed with oesophageal cancer in 1995,2000 and 2005

\begin{tabular}{|c|c|c|c|c|}
\hline \multirow[t]{2}{*}{ Grade } & \multirow[t]{2}{*}{ Description } & \multicolumn{3}{|c|}{ Percentage of patients } \\
\hline & & $1995(n=161)$ & $2000(n=103)$ & $2005(n=66)$ \\
\hline 0 & $\begin{array}{l}\text { Fully active, able to carry out all pre-disease } \\
\text { performance without restriction. }\end{array}$ & 14.9 & 18.5 & 3 \\
\hline I & $\begin{array}{l}\text { Restricted in physically strenuous activity, but } \\
\text { ambulatory and able to carry out work of light or } \\
\text { sedentary nature, e.g. light house work, office work. }\end{array}$ & 36 & 30.1 & 43.9 \\
\hline II & $\begin{array}{l}\text { Ambulatory and capable of self-care, but unable to } \\
\text { carry out any work activities; up and about more than } \\
50 \% \text { of waking hours. }\end{array}$ & 27.3 & 27.2 & 25.8 \\
\hline III & $\begin{array}{l}\text { Capable of limited self-care, confined to bed or chair } \\
\text { more than } 50 \% \text { of waking hours. }\end{array}$ & 14.9 & 20.4 & 22.7 \\
\hline IV & $\begin{array}{l}\text { Completely disabled - cannot carry out any self-care, } \\
\text { totally confined to bed or chair. }\end{array}$ & 6.8 & 3.9 & 4.6 \\
\hline
\end{tabular}

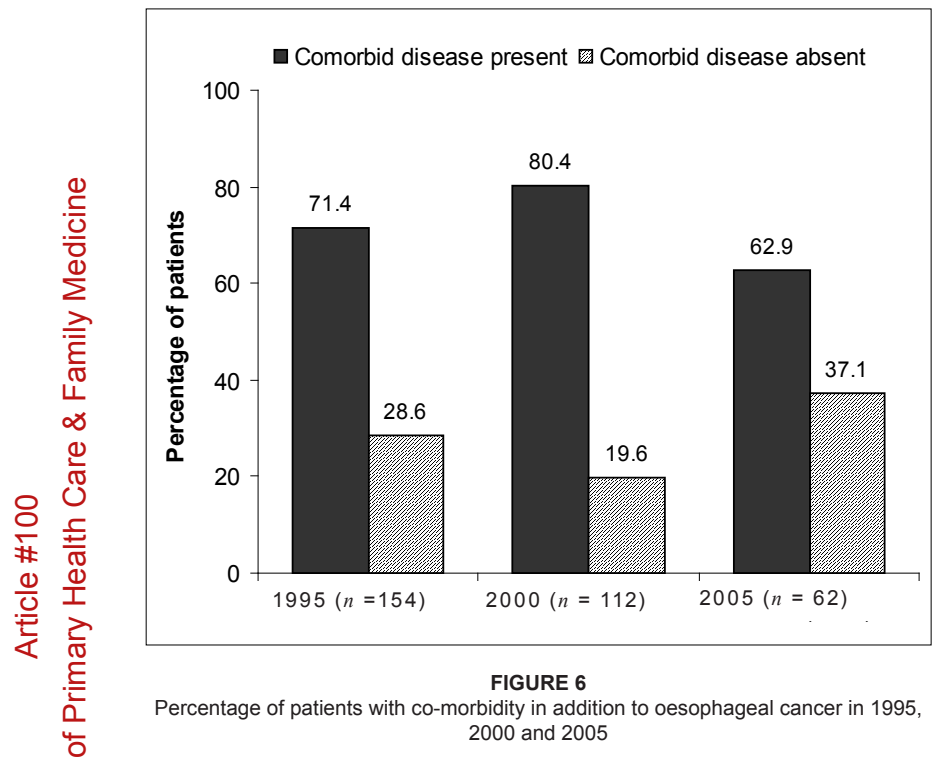

deaths in South African adults occur between 25 and 44 years of age. ${ }^{14}$ Additionally, the number of patients from other provinces, for example, the Eastern Cape, who previously visited National Hospital, could have decreased due to health policies preventing patients from one province visiting health care facilities in a neighbouring province. Insufficient primary health care, with poor diagnosis and referral of oesophageal carcinoma cases from clinics, could also have contributed to the decrease in the number of cases reported at the National Hospital from 1995 to 2005.

The racial distribution of oesophageal cancer remained fairly constant for the years 1995, 2000 and 2005 and reflected the general composition of the South African population. ${ }^{15}$ This observation could also be attributed to the fact that more Black patients visit National Hospital, especially the previously disadvantaged who could not afford medical aid as a result of historic disparities. Squamous cell carcinoma of the oesophagus was the most prevalent morphological type in all three years, and it could be concluded that this type of oesophageal cancer most commonly occurs in Black patients.

The gender distribution of patients with oesophageal cancer remained fairly constant for the years 1995, 2000 and 2005. The slight increase in the percentage of female patients in 2005 could possibly be attributed to an increase in tobacco ${ }^{16}$ and alcohol consumption ${ }^{17}$ in women in general over this period of time.

With regard to the histological type of oesophageal cancer, squamous cell carcinoma increased steadily. The percentage of cases presenting with adenocarcinoma remained constant at less than 3\% for the years 1995, 2000 and 2005. These findings are similar to results published by Cherian et al., ${ }^{18}$ who reported squamous cell carcinoma in $92 \%$ of patients with oesophageal malignancy in India between 1989 and 2004. Contrary to these findings, several studies reported an increase in the number of patients diagnosed with adenocarcinoma of the oesophagus. ${ }^{19,20,21,22}$

Dysphagia is a common symptom in oesophageal cancer and was observed in more than $85 \%$ of the study population. Weight loss, which is directly associated with dysphagia, occurred in more than $90 \%$ of patients. However, it should be kept in mind that the treatment of malignancies and the disease process could also contribute to physical deterioration.

Due to the retrospective nature of the study, information regarding certain aspects of the disease was lacking in many patient files. The reliable interpretation of some results was thus not possible. For example, patients could have died from local disease before extra-oesophageal extension of the tumour (indicated in only 49 [10.3\%] patient files) and metastasis of the malignancy (indicated in 180 [38.0\%] files) could be diagnosed. In addition, only $5 \%$ of patients with oesophageal carcinoma develop fistulae or sinuses, ${ }^{2}$ which could explain the high number of patient files not containing information regarding these complications.

\section{CONCLUSION}

The findings of this study showed that, for the years 1995, 2000 and 2005, the majority of patients with oesophageal cancer were Black middle-aged to elderly males who were diagnosed with squamous cell carcinoma. Although an increase in the number of cases presenting with squamous cell carcinoma of the oesophagus was noted, other variables, such as race, age and gender, remained constant for these three years.

\section{ACKNOWLEDGEMENTS}

We gratefully acknowledge Mr Ishmael Kopi at the National Hospital, Bloemfontein, for his assistance with patient files and Ms Daleen Struwig (medical writer, Faculty of Health Sciences, University of the Free State), for the technical and editorial preparation of the manuscript for publication.

\section{REFERENCES}

1. Lord RV, Law MG, Ward RL, Giles GG, Thomas RJ, Thursfield $\mathrm{V}$. Rising incidence of oesophageal adenocarcinoma in men in Australia. J Gastroenterol Hepatol. 1998;13(4):356-362.

2. Huang GJ. Natural progression of esophageal carcinoma. In: Delarue NC, Wilkins EW Jr, Wong J, editors. Esophageal Cancer: International Trends in General Thoracic Surgery. Volume 4. St. Louis: CV Mosby Company; 1988; p. 87-89. 
3. Huang GJ. Recognition and treatment of the early lesion. In: Delarue NC, Wilkins EW Jr, Wong J, editors. Esophageal Cancer: International Trends in General Thoracic Surgery. Volume 4. St. Louis: CV Mosby Company; 1988; p. 149-154.

4. Segal I, Reinach SG, De Beer M. Factors associated with oesophageal cancer in Soweto, South Africa. Br J Cancer. 1988;58(5):681-686.

5. Day NE. The geographic pathology of cancer of the oesophagus. Br Med Bull. 1984;40(4):329-334.

6. Enzinger PC, Mayer RJ. Esophageal cancer. N Engl J Med. 2003;349(23):2241-2252.

7. Lagergren L. Adenocarcinoma of the oesophagus: What exactly is the size of the problem and who is at risk? Gut. 2005;54(suppl)):i1-5.

8. Gonzales CA, Jakszyn P, Pera G, et al. Meat intake and risk of stomach and esophageal adenocarcinoma within the European Prospective Investigation Into Cancer and Nutrition (EPIC). J Natl Cancer Inst. 2006;98(5):345-354.

9. Lagergren J, Ye W, Lindgren A, Nyrén O. Heredity and risk of cancer of the esophagus and gastric cardia. Cancer Epidemiol Biomarkers Prev. 2000;9(7):757-760.

10. SAS Institute Inc. SAS Version 9.1 [CD-ROM]. Cary: SAS Institute Inc; 2002-2003.

11. Oken MM, Creech RH, Tormey DC, et al. Toxicity and response criteria of the Eastern Cooperative Oncology Group. Am J Clin Oncol. 1982;5(6):649-665.

12. Wijnhoven BP, Tran KT, Esterman A, Watson DI, Tilanus HW. An evaluation of prognostic factors and tumour staging of resected carcinoma of the esophagus. Ann Surg. 2007;245(5):717-725.

13. Nagel G, Linseisen J, Boshuizen HC, et al. Socioeconomic position and the risk of gastric and oesophageal cancer in the European Prospective Investigation into Cancer and Nutrition (EPIC-EURGAST). Int J Epidemiol. 2007;36(1):66-76.
14. South African Medical Research Council. What is the impact of HIV / AIDS in South Africa? [homepage on the Internet]. C2007 [updated 2007 Feb 10; cited 2008 Nov 11]. Available from: http://www.mrc.ac.za/bod/faqaids.htm

15. Statistics South Africa. Mid-year population estimates 2009 [document on the Internet]. c2009 [cited 2009 Oct 16]. STASSA publication P0302. Available from: http://www. statssa.gov.za/publication/P0302/P03022009.pdf

16. Centers for Disease Control and Prevention (CDC). Smoking and tobacco use. Women and smoking. 2001 Surgeon General's Report [document on the Internet]. c2001 [cited 2009 Oct 16]. Available from: http://www.cdc.gov/ tobacco/data_statistics/sgr/2001/

17. Crome IB, Kumar MT. Epidemiology of drug and alcohol use in young women. Semin Fetal Neonatal Med. 2007;12:98-105.

18. Cherian JV, Sivaraman R, Muthusamy AK, Jayanthi V. Carcinoma of the esophagus in Tamil Nadu (South India): 16-year trends from a tertiary center. J Gastrointestin Liver Dis. 2007;16(3):245-249.

19. Devesa SS, Blot WJ, Fraumeni JF Jr. Changing patterns in the incidence of esophageal and gastric carcinoma in the United States. Cancer. 1998;83(10):2049-2053.

20. Brown LM, Devesa SS. Epidemiologic trends in esophageal and gastric cancer in the United States. Surg Oncol Clin N Am. 2002;11(2):235-256.

21. El-Serag HB, Mason AC, Petersen N, Key CR. Epidemiological differences between adenocarcinoma of the oesophagus and adenocarcinoma of the gastric cardia in the USA. Gut. 2002;50(3):368-372.

22. WeiJT, Shaheen N. The changing epidemiology of esophageal adenocarcinoma. Semin Gastrointest Dis. 2003;14(3):112-127. 